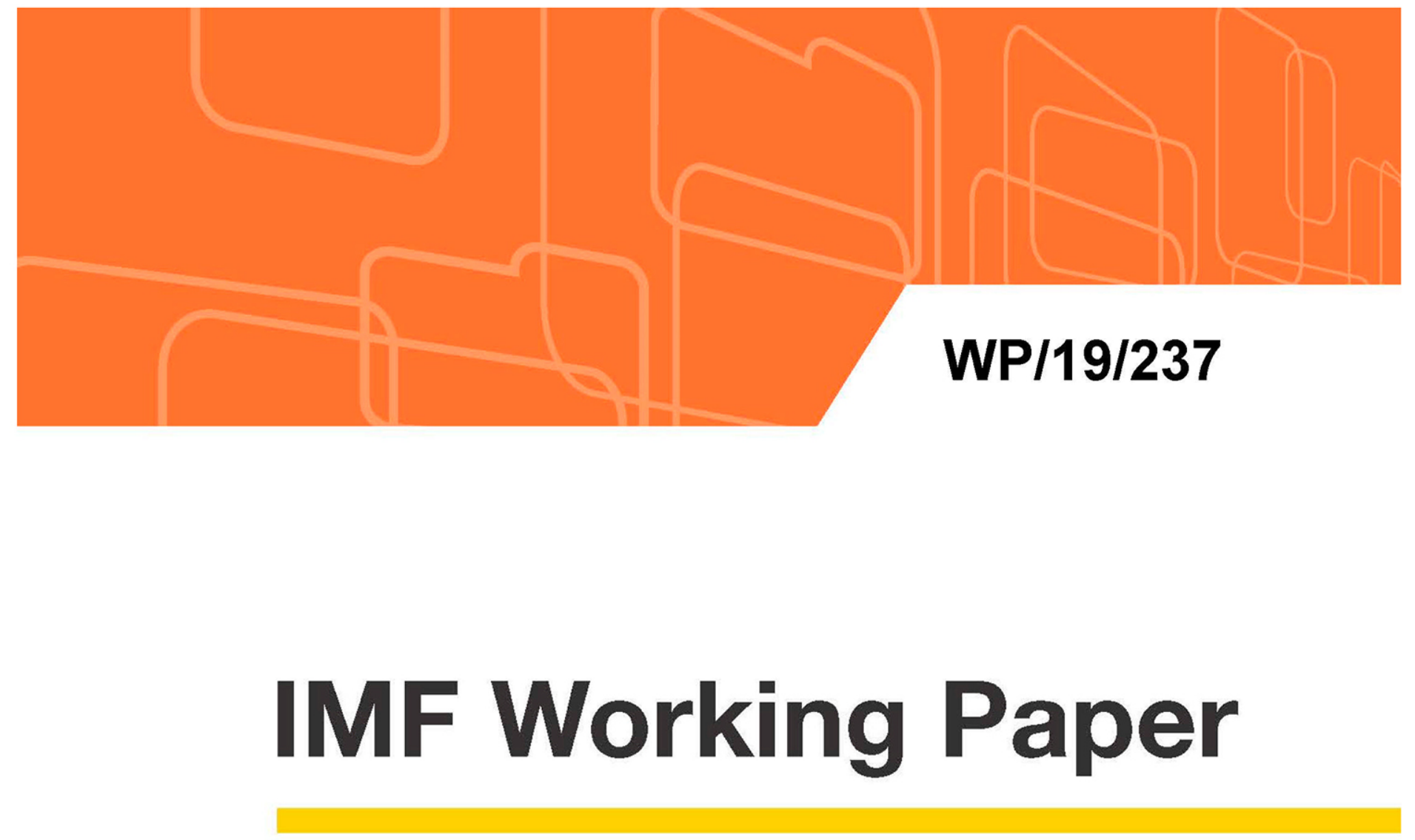

\title{
Granger Predictability of Oil prices after the Great Recession
}

\author{
By Szilard Benk, Max Gillman
}

IMF Working Papers describe research in progress by the author(s) and are published to elicit comments and to encourage debate. The views expressed in IMF Working Papers are those of the author(s) and do not necessarily represent the views of the IMF, its Executive Board, or IMF management. 


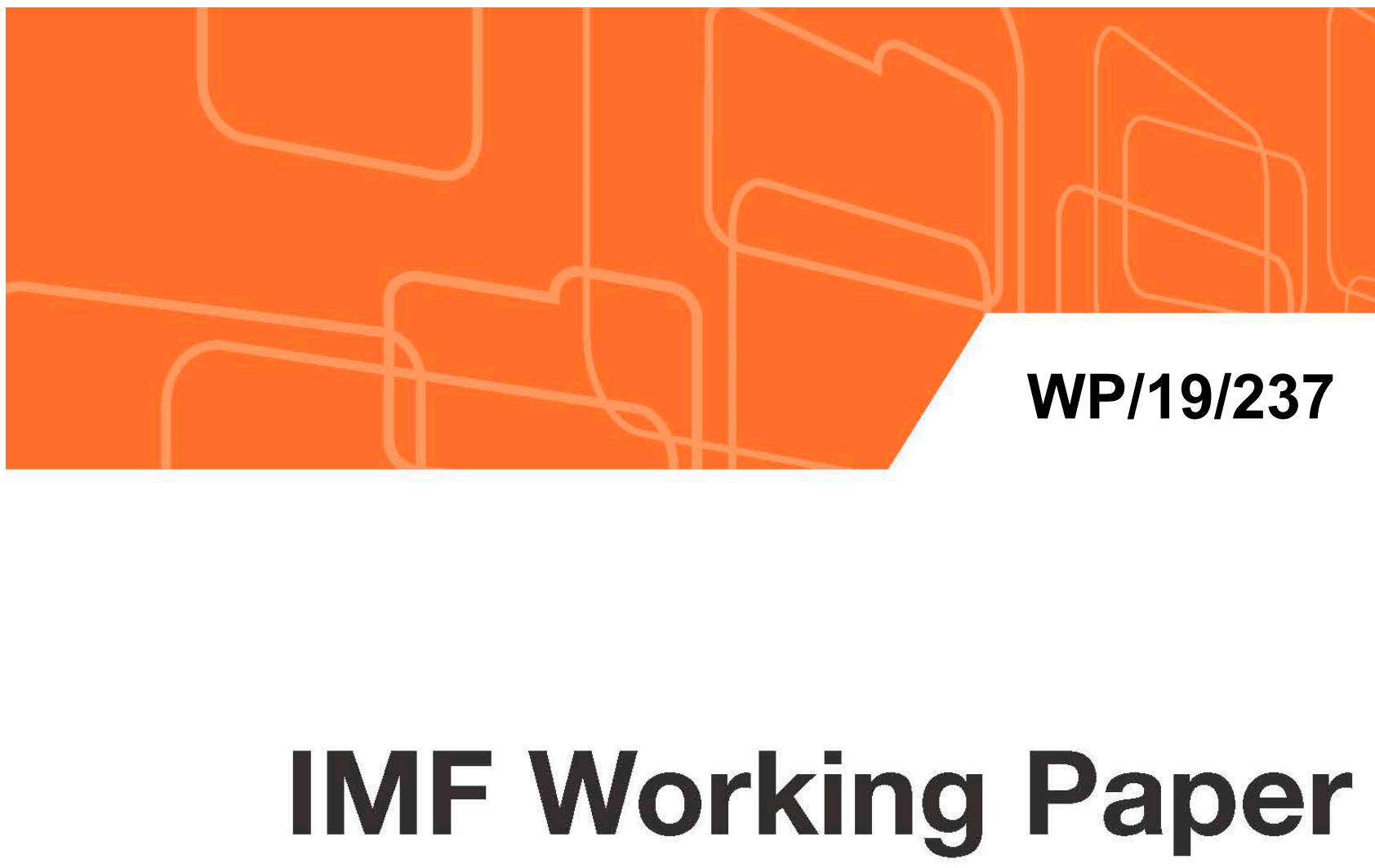

\title{
Granger Predictability of Oil prices after the Great Recession
}

\author{
By Szilard Benk, Max Gillman
}

IMF Working Papers describe research in progress by the author(s) and are published to elicit comments and to encourage debate. The views expressed in IMF Working Papers are those of the author(s) and do not necessarily represent the views of the IMF, its Executive Board, or IMF management. 


\title{
IMF Working Paper
}

Office of Executive Director

\author{
Granger Predictability of Oil prices after the Great Recession+ \\ Prepared by Szilard Benk*, Max Gillman** \\ Authorized for distribution by Raci Kaya
}

November 2019

\begin{abstract}
IMF Working Papers describe research in progress by the author(s) and are published to elicit comments and to encourage debate. The views expressed in IMF Working Papers are those of the author(s) and do not necessarily represent the views of the IMF, its Executive Board, or IMF management.
\end{abstract}

\begin{abstract}
Real oil prices surged from 2009 through 2014, comparable to the 1970's oil shock period. Standard explanations based on monopoly markup fall short since inflation remained low after 2009. This paper contributes strong evidence of Granger (1969) predictability of nominal factors to oil prices, using one adjustment to monetary aggregates. This adjustment is the subtraction from the monetary aggregates of the 2008-2009 Federal Reserve borrowing of reserves from other Central Banks (Swaps), made after US reserves turned negative. This adjustment is key in that Granger predictability from standard monetary aggregates is found only with the Swaps subtracted.
\end{abstract}

JEL Classification Numbers: Q43, E510, E520

Keywords: Oil Price Shocks, Granger Predictability, Monetary Base, M1 Divisia, Swaps, Inflation.

Authors' E-Mail Address: * International Monetary Fund, benk.szilard@gmail.com, ** University of Missouri - St. Louis, Department of Economics gillmanm@umsl.edu

+We are grateful to University of Missouri, Friedrich A. Hayek Chair endowment funding, and for excellent discussion points at the AEA 2018 Winter Meetings by Jonathan Lee, East Carolina University, and for the comments at the 6th International Symposium on Environment and Energy Finance Issues (ISEFI-2018), especially by Lutz Kilian, and with special thanks to Michal Bordo and Owen F. Humpage. 


\section{Introduction}

Oil shocks have been explained by episodes of unrest (Baumeister and Kilian, 2016), supply and demand (Kilian, 2009), monopoly power (Mankiw, 2014), and by money supply growth (Alquist et al., 2013). There is a lack of consensus especially about the 2009-2014 oil price "shock". For example, unrest and monopoly power theses are countered by US oil fracking creating a tremendous oil supply increase during the 2009-2014 period.

The monetary hypothesis is intriguing since Alquist et. al (2013) show that the US CPI inflation rate, the US monetary base and the US M1 monetary aggregate all Granger (1969) predict oil prices with a post-WWII data sample ending in 2009. These results stand in contrast to Hamilton's famous (1983) results that no macroeconomic series Granger predicts oil prices; but this is not surprising in that Hamilton's data ended in 1972 before oil prices became free floating in spot markets after the end of the Bretton Woods Monetary agreement, making such econometric testing weak. This paper contributes evidence that neither the standard monetary aggregates nor the US CPI Granger predict oil prices in the 2008-2017 subperiod, but with one adjustment to the monetary aggregates, such Granger predictability does indeed hold strongly.

The problem for which this paper contributes a solution is why the US money supply and CPI inflation do not Granger predict oil prices for the 2008-2017 subperiod as they do for early periods. When including the recent 2009-2014 oil shock, none of the standard monetary aggregates Granger predict oil prices for all subperiods examined. However, this conundrum is "solved" by considering that, in 2008-2009, the liquidity crisis among the investment banks not insured by the FDIC led to the Fed borrowing reserves from other international central banks in order to shore up reserves that had become negative in 2008 during the peak bank crisis time.

In particular, from August 2008 to December 2008, the Fed's excess reserves shot up from less than zero to $\$ 600$ Billion through the Central Bank Liquidity Swaps (on Federal Reserve Economic Data base: SWPT). These Swaps were quickly "unwound", which means paid back, by April 2009. But excess reserves at that time then continued to grow as the Fed bought more Treasury debt while paying interest on excess reserves (IOER: paid for the first time ever starting in October 2008).

The initial 2008 spike in excess reserves as a result of the Swaps caused the US monetary base to rise. Concurrently international asset markets broadly declined. The 2008 decline included US stock markets, gold prices, and oil prices. Our paper shows that the opposite movement of oil prices going down, while the Swap-augmented monetary base (the standard MB definition) was going up, breaks up Granger predictability of the monetary base (MB), of M1, and of M1 -Divisia to real oil prices.

Formally the Swaps are counted as a part of the US monetary base. ${ }^{1}$ But since the

\footnotetext{
${ }^{1}$ We owe this point to Michal Bordo and Owen F. Humpage.
} 
Swaps were a temporary measure for the bank liquidity crisis, rather than part of inflationpressure inducing reserve increases, we calculated the monetary aggregates with these Swaps subtracted out. As Bordo et al. (2014) show in their history of the Swaps, subtracting these out has little effect on the monetary aggregates except during 2008-2009.

Using what we call MB-SWP for the monetary base minus the Swaps, as well as M1 minus the Swaps (M1-SWP) and M1-Divisia minus the Swaps, we find robust Granger predictability of these monthly adjusted aggregates to oil prices both real and nominal (the latter results are not reported). It is a simple finding, but one perhaps of importance for understanding this 2009-2014 oil shock. The Granger predictability of real oil prices by the Swap adjusted aggregates holds at a $1 \%$ level of significance in terms of p-values, for M1-SWP for most subperiods and the full sample, and for MB-SWP for the full sample.

We also report when reverse causality exists at a $10 \%$ level of significance, none of which is found for the monetary aggregates in the 2008-2017 subperiod. Extensions emphasize how the nominal effects are broader than to just oil prices. For the 2008-2017 subperiod, there is also Granger predictability without the reverse, from: M2 minus Swaps to real gold prices; from M1-SWP, M2-SWP, M1Divisia-SWP, and M2Divisia-SWP to the oil to gold price ratio; and from the MB-SWP to the US dollar exchange rate index.

The paper also reports robust Granger predictability of CPI inflation by the MB and MB-SWP for all subperiods. The hypothesis of why real oil prices went up so high in 2009-2014 while US inflation was subdued is that the monetary base shot up, such that expectations of future long-term inflation increased and were in turn reflected in oil prices. Using the "5-Year Breakeven Inflation Rate" measure of inflation expectations (denoted here by EXP5Y), as given on the Federal Reserve Economic Data (FRED) database beginning in $2003,{ }^{2}$ this hypothesis is confirmed to the extent that this inflation expectations variable, EXP5Y, Granger predicts real oil prices for the whole sample and for the 2008-2017 period (p-value $<0.01 ;$ no reverse causality for 2008-2017). This inflation expectations variable also Granger predicts the oil to gold price ratio for the same subperiods. Short term expectations also factor in.

Using the Michigan Survey for the "median expected price change next 12 months" as a measure of short run inflation expectations (EXPMICH), this Granger predicts real oil prices and the oil to gold price ratio for the 1991-2017 subperiod, as well as gold prices for the period up to 2008, and US dollar exchange rates for the whole sample period. In sum, only the longer-term inflation expectations measure helps explain oil prices in the 2008-2017 period, while short run inflation expectations also find a role in explaining oil prices in the 1991-2008 subperiod.

\footnotetext{
2 "The breakeven inflation rate represents a measure of expected inflation derived from 5-Year Treasury Constant Maturity Securities and 5-Year Treasury Inflation-Indexed Constant Maturity Securities. The latest value implies what market participants expect inflation to be in the next 5 years, on average" (FRED online description)
} 
Section 2 describes the literature and some empirical trends. Section 3 provides the data sources, Section 4 presents the econometric methodology and data testing, and Section 5 the results. Section 6 offers some discussion, and Section 7 concludes.

\section{Literature and Empirical Facts}

Subtracting out the Swaps is similar in spirit perhaps to how Lucas and Nicolini (2015) use an adjusted M1 to find a stable money demand function. They expand the definition of M1, which they call M1MMDA, by taking money market deposit accounts from M2 and adding them to M1. Here we also are focusing in on what is the relevant monetary aggregate, in our case, to see whether monetary factors help explain oil prices.

A monetary theory of oil shocks was presented descriptively by Barsky and Kilian (2004) for the 1970's. Using data up to 2006, Gillman and Nakov (2009) provide evidence of Granger predictability of nominal oil prices by inflation. Their accompanying perfect foresight model shows how nominal oil prices need to jump in response to jumps in the inflation rate simply to keep the real return to oil (and gold) investment constant. From this view, the 1970's oil shocks were "catching-up" for fifteen years of declining real oil prices; they show how oil price movements follow inflation closely starting after the early 1980's. Alquist et al. (2013) show robustness of these causality finds from inflation to oil prices, using data from 1975 to 2009, and also show Granger predictability of M1 to oil prices. ${ }^{3}$

Consider four key nominal data series of interest here. Figure 1 graphs the natural $\log$ of US dollar data monthly from January 1, 1947 to May 1, 2017: The WTI spot oil price (solid), the Consumer Price Index (CPI, dashed), the Monetary Base (dotted), and the "Gold Fixing Price" (grey). The CPI series and the Gold series are shifted down for comparison to the other two series. Certainly the oil and normalized gold prices appear to move rather closely together. And broadly, one can see how both of these commodity series have some broad comovement with the CPI and with the monetary base. Further, the post2008 jump in the monetary base seems to comove somewhat closely with the oil price; both turn downwards at nearly the same time in 2014. The WTI oil price fell from 106 in June 2014 down to 47 in January 2015. Almost simultaneous, in August 2014, "Excess Reserves" of the Fed (data series EXCSRESNS) reached its all-time peak and dropped steadily until

\footnotetext{
${ }^{3}$ Alquist, Kilian and Vigfussion (2011, pp.11-12): "There are several reasons to expect the dollardenominated nominal price of oil to respond to changes in nominal U.S. macroeconomic aggregates. One channel of transmission is purely monetary and operates through U.S. inflation. ... Indeed, the Grangercausality tests in Table 1a indicate highly significant lagged feedback from U.S. headline CPI inflation to the percent change in the nominal WTI price of oil for the full sample....an alternative approach of testing ... is to focus on Granger causality from monetary aggregates to the nominal price of oil. Given the general instability in the link from changes in monetary aggregates to inflation, one would not necessarily expect changes in monetary aggregates to have much predictive power for the price of oil, except perhaps in the 1970s (see Barsky and Kilian 2004). Table 1a nevertheless shows that there is considerable lagged feedback from narrow measures of money such as M1 for the refiners' acquisition cost and the WTI price of oil based on the 1975.2-2009.12 evaluation period."
} 


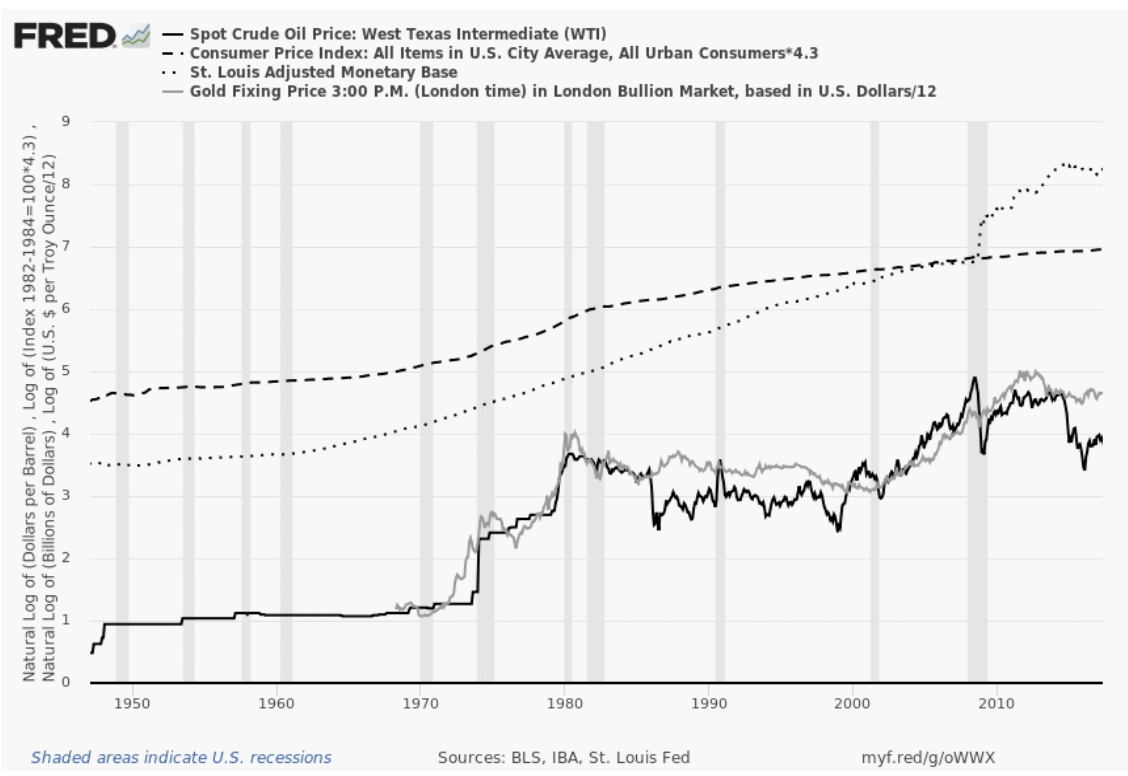

Figure 1: Oil, CPI, Monetary Base, and Gold post-WWII Data Series.

hitting its current $\$ 2$ trillion range.

For January 1, 1947 to May 1, 2017, Figure 2 shows in addition to the dollar, nominal, WTI price (solid), the real WTI price (grey). The real price is derived by dividing the WTI by the CPI for all Urban consumers $(1982=100)$, and normalized by dividing by 100 . Also drawn are endpoint to endpoint trend lines in dotted lines. The black dotted line endpoints trend is from $\$ 1.62$ to $\$ 52.50$. Calculating $\frac{52.5-1.62}{1.62}=31.4$, gives a $3,141 \%$ increase. In contrast, the average annual real oil price increase is from 7.54 to 19.88 , a $\frac{19.88-7.54}{7.54}=1.64$, or a $164 \%$ increase. This gives an average annual real oil price increase at an annualized rate over the 70 years of about $1.4 \%$ increase per year; this return resembles some trend estimates of the average real interest rate in the US over this period, suggesting that recent oil prices are not out of line with historical capital returns.

Figure 3 provides growth rates for the CPI and the monetary base. It graphs the natural $\log$ of each data series so that the slopes of the series indicates the growth rate. Over the same 70.25 years, Figure 3 shows the CPI index and its grey dotted trend line, as compared to the upper graph of the monetary base and its trend lines, as presented in three sections of the trend. These three sections are in grey dash lines, separate for the first years, up until the Great Recession, and then steeper slope trend line for after 2008. The CPI index rises from 21.48 to 243.846 in the lower graph, for a 10.35 -fold increase. The monetary base rose by much more, especially after 2008.

In Figure 3, from January 1, 1947 to January 1, 1960, the slope of the arc (not shown) 


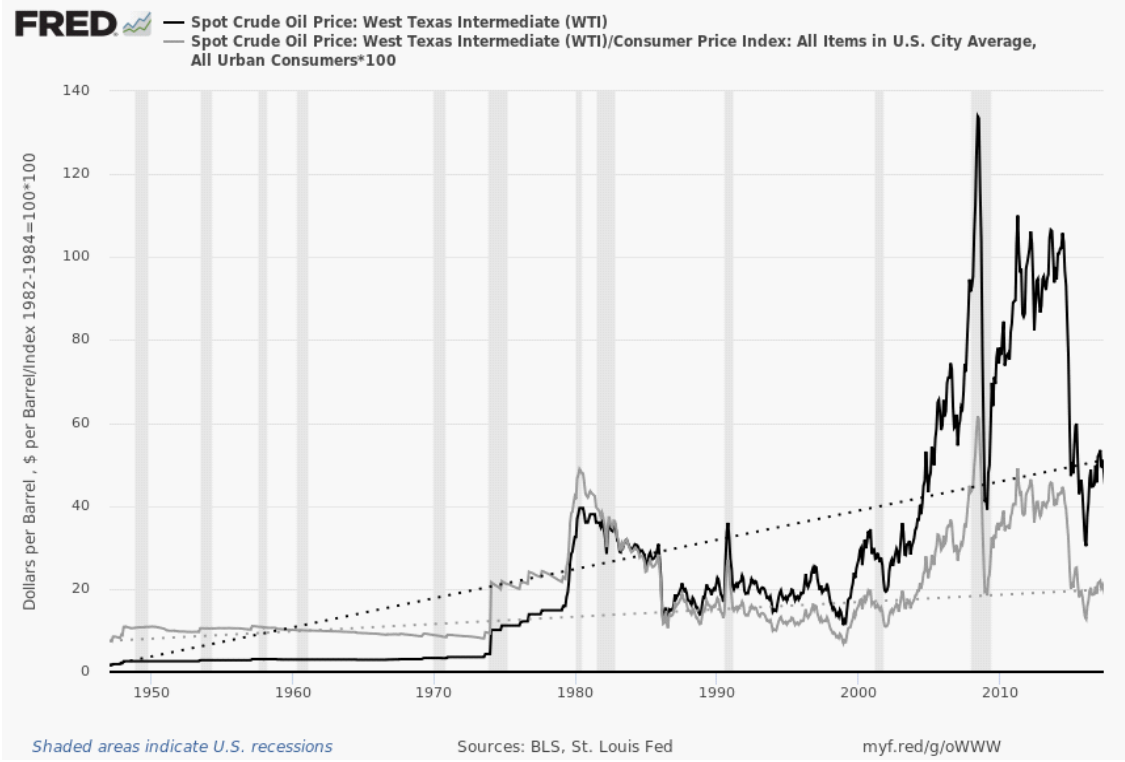

Figure 2: Nominal and Real WTI Oil Prices, with trend lines.
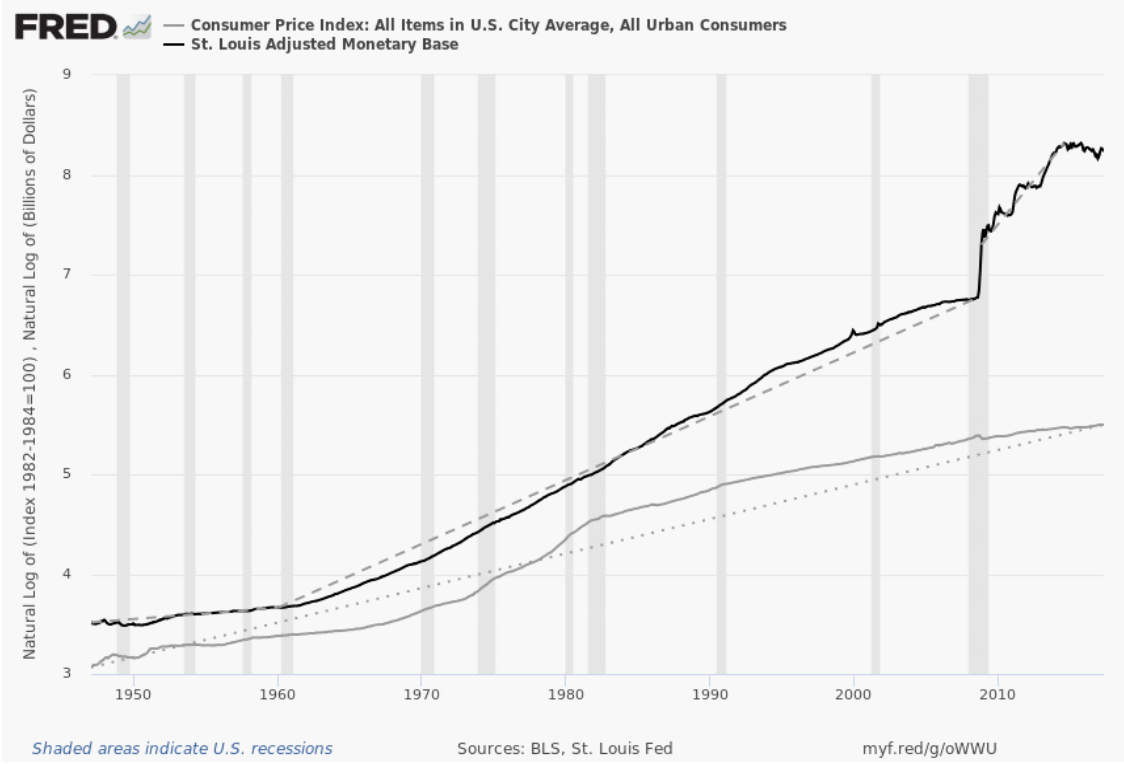

Figure 3: Natural Log of CPI and Monetary Base, 1947-2017. 


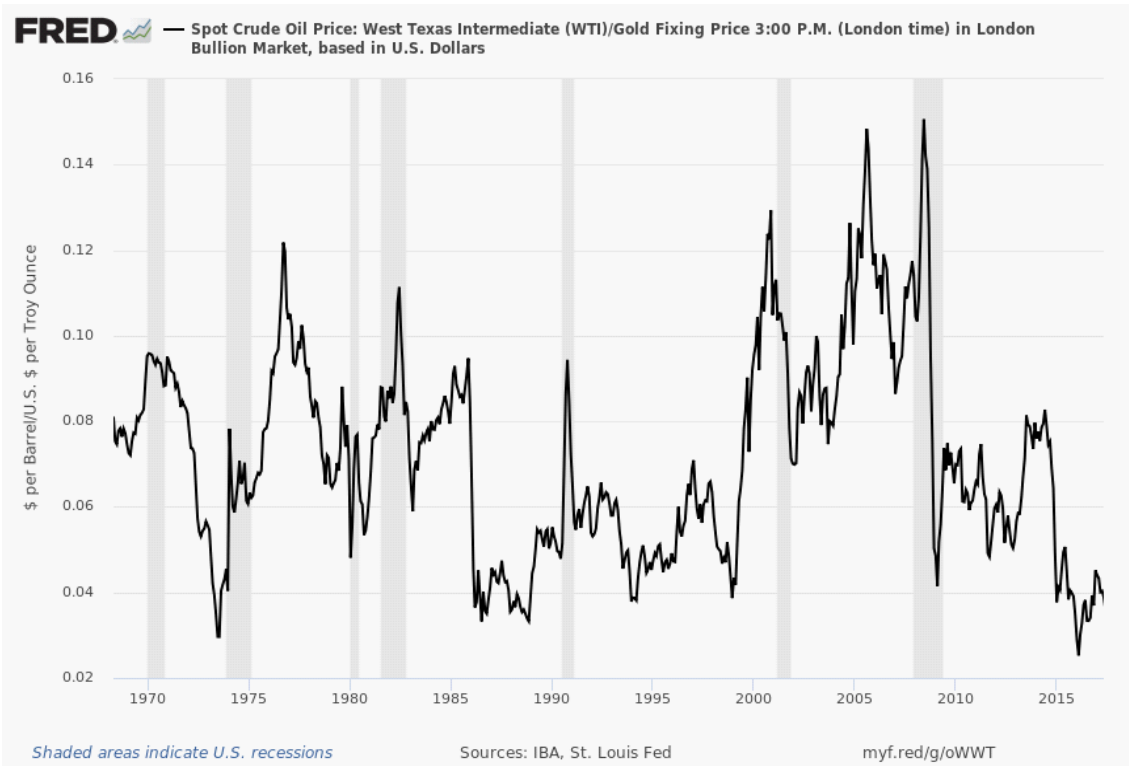

Figure 4: Oil to Gold Price Ratio

of the CPI line indicates an annual average of $\frac{3.38-3.076}{13}=0.0234$; or $2.3 \%$. For the arc line segment for the CPI from 1-1-1960 to 1-1-1982 (not shown), the annual average increase is $\frac{4.547-3.38}{12}=0.097$. This shows the acceleration of inflation during the Vietnam war; however the actual average rate of increase is less than this since the data forms a convex curve below the arc. Then from January 1, 1982 to August 1, 2008, the arc (not shown) slope indicates a $\frac{5.387-4.547}{26.583}=0.0554$, or a $5.54 \%$ average. From 10-1-2008 to 5-1-2017, the arc (not shown) slope decreases to $\frac{5.50-5.387}{8.75}=0.013$, or a $1.3 \%$ average annual inflation rate. These form four markedly different "regimes". The first three are broadly shadowed by the monetary base; the fourth and last one is not.

Given the seeming graphical comovement of oil and gold prices, Figure 4 shows that this series, starting with the FRED data for gold in 1968, looks somewhat like random noise. It may be that a nominal story can be told for some movements in the series, or the opposite type of thesis, that of relative price changes from supply or demand shifts, may apply. As an extension, this oil/gold price is also tested for nominal causality.

Figure 5 shows the monetary base, along with the monetary base minus the Central Bank Liquidity Swaps. It also includes the Excess Reserves minus the Swaps. Subtracting the Swaps from Excess Reserves shows that these reserves turned negative in April 2008, with a negative peak in October 2008.

Figure 6 shows the Swaps themselves. Though the magnitude of the Swaps themselves is small, they caused reserves to rise when oil prices were crashing along with other asset 


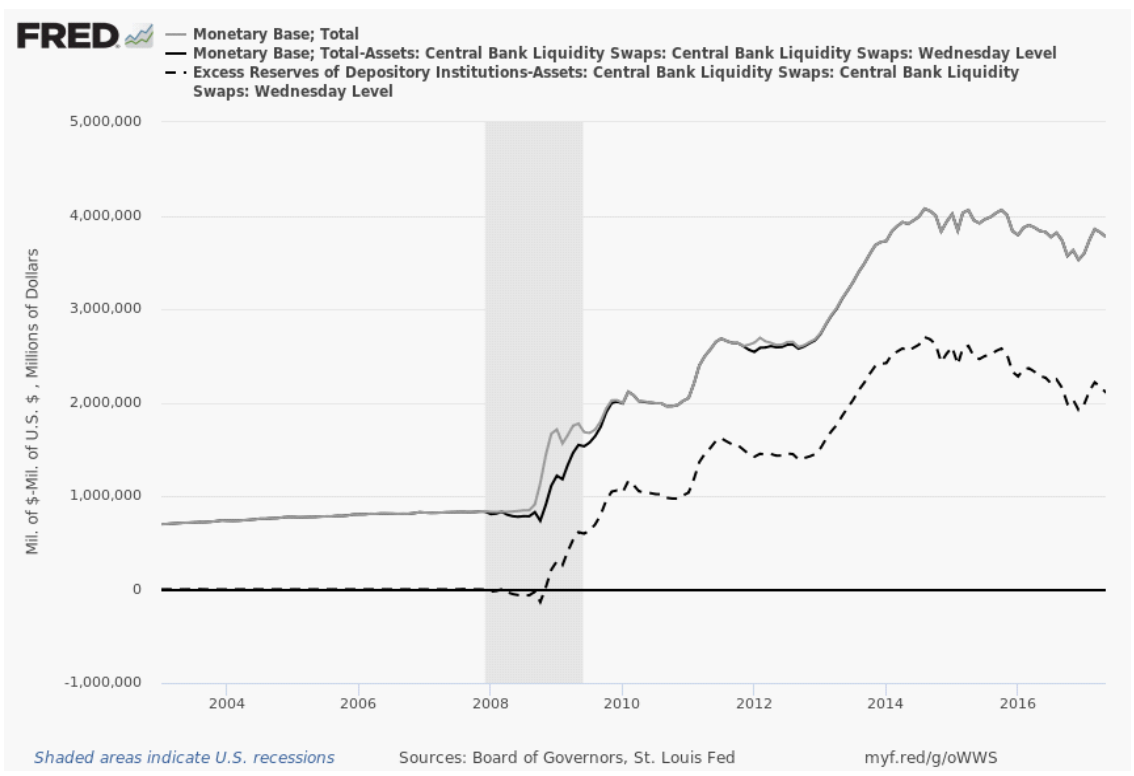

Figure 5: Monetary Base; Monetary Base minus Swaps; Excess Reserves minus Swaps turned Negative in 2008.

prices. Subtracting these Swaps back out, on the basis of their use for stemming a panic rather than for increasing the money supply per se, provides a small change in the monetary aggregates, but one that is key for finding a monetary effect on oil prices.

\section{Data}

Monthly data is from the FRED database (Federal Reserve Economic Data base of the Federal Reserve Bank of St. Louis), with the FRED code and the full period available as indicated in parenthesis:

MB: Money Base (AMBSL, 1946m1 - 2017m4)

SWP: Central Bank Liquidity Swaps (SWPT, 2003m1 - 2017m5)

DEMDEP: Demand deposits (DEMDEPSL, 1959m1 - 2017m4)

M1: M1 Money Stock (M1SL, 1959m1 - 2017m4)

M2: M2 Money Stock (M2SL, 1959m1 - 2017m4)

CPIE: CPI less Energy (CPILEGSL, 1957m1 - 2017m4)

CPI: CPI for all urban consumers (CPIAUCSL, 1947m1 - 2017m4)

WTI: Spot Crude Oil Price WTI (WTISPLC, 1946m1 - 2017m4)

GOLD: Gold fixing price, London Bullion (GOLDPMGBD228NLBM, 1968m4-2017m5)

M1Divis: Monetary services Index M1 (MSIM1P, 1967m1 - 2013m12) 


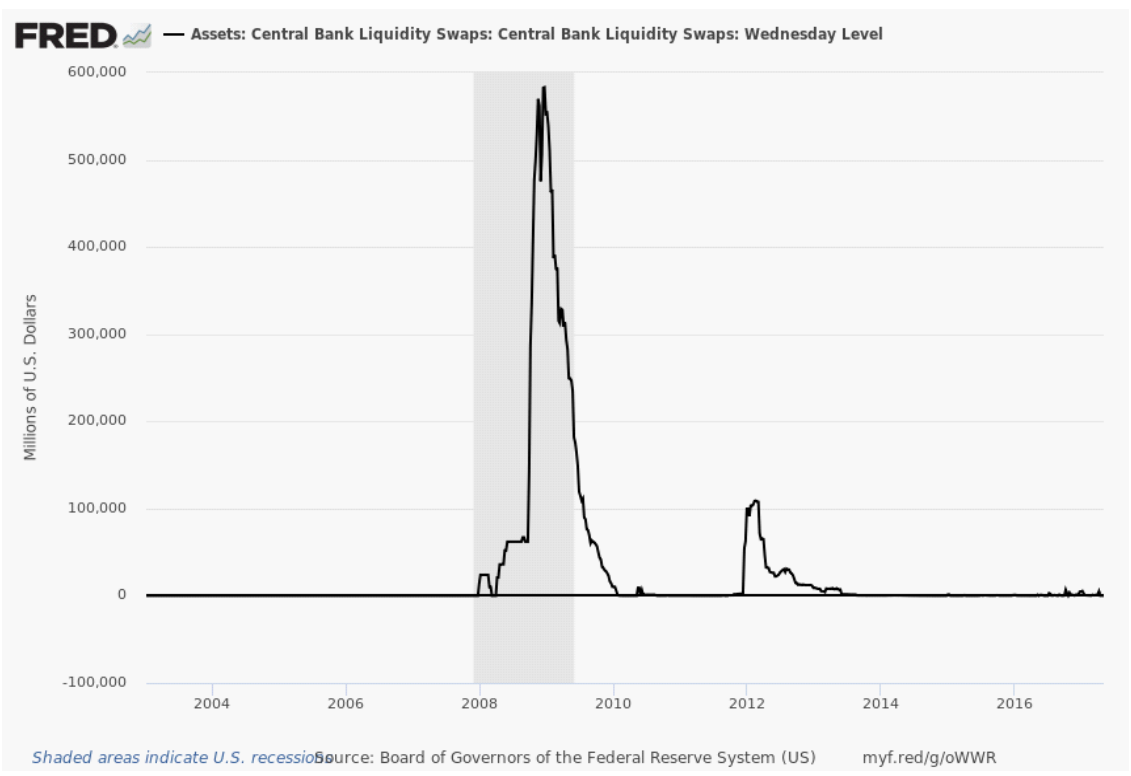

Figure 6: Central Bank Liquidity Swaps; Peak at $\$ 580$ Billion in December 2008

M2Divis: Monetary services Index M2 (MSIM2, 1967m1 - 2013m12)

EXCH: Trade Weighted U.S. Dollar Index: Broad (TWEXB, 1973m1 - 2017m4)

EXP5Y: 5-Year Breakeven Inflation Rate (T5YIEM, 2003m1 - 2017m12)

EXPMICH: University of Michigan Inflation Expectation (MICH, 1978m1 - 2017m12)

EXCESS: Excess reserves of Depository Institutions (EXCSRESNS, 1984m2 - 2017m4).

\section{Testing Methodology and Data Properties}

The testing methodology is similar to Hamilton (1983), Gillman and Nakov (2009) and Alquist, Kilian and Vigfusson (2013), as based on Granger (1969). This involves estimating a VAR model of the following form:

$$
Y_{t}=c_{0}+c_{1} Y_{t-1}+\ldots . .+c_{p} Y_{t-p}+d_{1} X_{t-1}+\ldots . .+d_{p} X_{t-p}+v_{t}
$$

Then $X$ is said to Granger-cause $Y$ if $Y$ can be better predicted using the histories of both $X$ and $Y$ than it can by using the history of $Y$ alone. This reduces to testing the null hypothesis $H_{0}: d_{1}=d_{2}=\ldots \ldots=d_{p}=0$, against $H_{A}$ : 'Not $H_{0}$ '. Rejection of the null is equivalent to saying that $X$ does Granger-cause $Y$.

The test requires that $X$ and $Y$ to be stationary or of the same order of integration. To determine the order of integration, we apply the Augmented Dickey-Fuller (ADF) test for unit roots. Should $X$ and $Y$ be integrated of the same order, the series are differentiated so as to become stationary. If integrated one order higher that their "pairs", we follow instead 
the Toda and Yamamoto (1995) procedure to test for Granger-causality, as described by Giles (2011).

Unit root and Granger-causality tests are run on the full sample and various subsamples. The breakpoints and subsamples have been chosen because of various considerations. Including post-1973 and post-1975 subperiods is motivated by Alquist, Kilian and Vigfusson (2013). The 2008:m9 breakpoint marks the point in the liquidity crisis when Swaps dramatically rose, thereby separating pre- and post-crisis periods on that basis.

All series for all variables and subperiods proved to be integrated of order 1 (I(1)), except for the CPIE (CPI without energy prices), and the EXP5Y and EXPMICH inflation expectations variables, which are I(2). We apply standard Granger (1969) causality tests to all the I(1) pairs of series, and the Toda and Yamamoto (1995) procedure to test for causality of the $\mathrm{I}(2)$ series on $\mathrm{I}(1)$ series.

\section{Results}

Table 1 reports results of Granger predictability of real oil prices by the monetary base minus swaps (MB-SWP) for the full sample, starting in 1947, for the 1975-2017 subperiod, and for the 2008-2017 subperiod, the latter with no reverse predictability. Reverse predictability with a p-value less than $10 \%$ is reported using the directional sign $<$ after the p-value number in all of the tables.

Note that the "Full Sample" and "Start-2008m9" subperiod indicates starting when the data series begins jointly for each data pair being tested. This implies starting points for example of 1947 for the MB and oil prices tests, and 1967 for similar gold price testing. Starting dates for the data series are given in each of the tables under the second column "Start".

Table 1 shows rejection of the monetary base Granger predicting oil prices in all subperiods. The same results hold for tests of M1. In contrast, for M1 minus Swaps (M1-SWP), results show a p-value below $1 \%$ for all post-WWII subperiods, with no reverse causality for the 2008-2017 period. Similar Granger predictability results hold for M1-Divisia minus Swaps, but not for M1-Divisia.

While the MB aggregate includes reserves, the M1 aggregate does not. So we constructed an aggregate by adding the monetary base to demand deposits (MB+DEMDEP), which is M1 plus reserves. This aggregate showed Granger predictability for one period, the full sample, while subtracting Swaps from this aggregate (MB-SWP+DEMDEP) results in Granger predictability in all but one subperiod, as in other narrow aggregates minus Swaps.

In Table 1, broader aggregates show no Granger predictability, in terms of M2, M2-SWP, M2-Divisia and M2-Divisia minus Swaps. Granger predictability by inflation indices of oil prices is reported for the CPI minus Energy prices (CPIE) for most of the subperiods, and 


\begin{tabular}{rrrrrrrr}
\hline \hline to Real Oil & Start & Full Sample & $1973-2017$ & $1975-2017$ & $1991-2017$ & Start-2008m9 & $2008 \mathrm{~m} 10-2017$ \\
\hline \hline MB & 1947 & $0.1305_{<}$ & 0.4985 & 0.4065 & 0.5728 & $0.7909_{<}$ & 0.7486 \\
MB-SWP & 1947 & $\mathbf{0 . 0 0 1 9}$ & $\mathbf{0 . 0 6 0 2}$ & $\mathbf{0 . 0 0 6 6}<$ & $\mathbf{0 . 0 2 4 1}$ & $0.9545_{<}$ & $\mathbf{0 . 0 5 3 8}$ \\
MB+DDep & 1959 & $\mathbf{0 . 0 7 5 0}$ & 0.2299 & 0.1288 & 0.1227 & $0.852_{<}$ & 0.299 \\
MB-SWP+DDep & 1959 & $\mathbf{0 . 0 1 5 1} 1_{<}$ & $\mathbf{0 . 0 8 1 6}$ & $\mathbf{0 . 0 0 9 5}$ & $\mathbf{0 . 0 2 4 6}$ & $0.9064_{<}$ & $\mathbf{0 . 0 2 4 4}$ \\
M1 & 1959 & $0.4581_{<}$ & 0.6533 & 0.4001 & 0.1983 & $0.8001_{<}$ & 0.3475 \\
M1-SWP & 1959 & $\mathbf{0 . 0 0 0 4}<$ & $\mathbf{0 . 0 0 6 7}<$ & $\mathbf{0 . 0 0 0 6}$ & $\mathbf{0 . 0 0 1 1}<$ & $0.793_{<}$ & $\mathbf{0 . 0 0 1 3}$ \\
M2 & 1947 & $0.7671_{<}$ & $0.8821_{<}$ & 0.8119 & $0.3224_{<}$ & 0.8405 & 0.5765 \\
M2-SWP & 1947 & $0.8882_{<}$ & 0.9326 & 0.8412 & 0.5326 & 0.8432 & 0.1393 \\
CPIE & 1957 & $\mathbf{0 . 0 0 2 1}$ & $\mathbf{0 . 0 0 0 1}<$ & 0.8309 & 0.4942 & $\mathbf{0 . 0 0 0 3}$ & $\mathbf{0 . 0 1 6 9}$ \\
CPI & 1947 & $0.1605_{<}$ & $\mathbf{0 . 0 1 8 7}$ & 0.1521 & $\mathbf{0 . 0 4 6 2}<$ & $\mathbf{0 . 0 5 7 2}$ & $0.5931<$ \\
EXP5Y & 2003 & $\mathbf{0 . 0 0 5 7}<$ & $\mathrm{N} / \mathrm{A}$ & $\mathrm{N} / \mathrm{A}$ & $\mathrm{N} / \mathrm{A}$ & 0.5126 & $\mathbf{0 . 0 0 3 2}$ \\
EXPMICH & 1978 & $0.6735_{<}$ & $\mathrm{N} / \mathrm{A}$ & $\mathrm{N} / \mathrm{A}$ & $\mathbf{0 . 0 0 6 3}<$ & $0.9121_{<}$ & $0.2458<$ \\
M1Divis & 1967 & $0.664_{<}$ & 0.7003 & 0.3634 & 0.3257 & $0.8704_{<}$ & 0.7573 \\
M1Divis-SWP & 1967 & $\mathbf{0 . 0 1 5 1}<$ & $\mathbf{0 . 0 3 2 3}<$ & $\mathbf{0 . 0 0 4 8}$ & $\mathbf{0 . 0 0 4 6}<$ & $0.9024_{<}$ & $\mathbf{0 . 0 0 1 6}$ \\
M2Divis & 1967 & $0.6046_{<}$ & $0.6439_{<}$ & 0.3758 & 0.165 & $0.8704_{<}$ & 0.5612 \\
M2Divis-SWP & 1967 & $0.8466_{<}$ & $0.8679_{<}$ & 0.7038 & 0.6873 & $0.8803_{<}$ & 0.3214 \\
\hline \hline
\end{tabular}

Note: $\mathrm{p}$ values in bold $(<0.10)$ indicate the presence of causality.

Subscript " $<"$ indicates reverse causality

Table 1: Causality to real oil price (WTI/CPI)

without reverse causality after 2008 and in other periods. For the regular CPI (for all urban consumers), there is Granger predictability for the Start of the sample up to 2008, without reverse predictability, but no predictability for the 2008-2017 period.

The long term inflation expectations is tested in terms of the 5 -year breakeven inflation rate (EXP5YR), which is constructed by the St. Louis Fed, with data starting in 2003. This shows evidence of Granger predictability, with no reverse predictability, for the 20082017 sample period. Shorter term expectations, in terms of the Michigan one-year ahead survey forecast (EXPMICH), show predictability for the 1991-2017 period, with reverse predictability, but not in the 2008-2017 sample period by itself. This confirms directly a predictability role of both long term and short term measures of inflation expectations in causing real oil prices.

The comovement of oil and gold prices seen in Figure 1 suggests also examining the Granger predictability by nominal factors on real gold prices. Table 2 shows that M1 minus Swaps, M1-Divisia minus Swaps, M2 minus Swaps and M2-Divisia minus Swaps all show Granger-causality of real gold prices for some of the post-WWII subperiods. M2-SWP shows such causality for the entire post 1950 "full sample" period, as well as for 1991-2017 and 2008-2017; there is no reverse causality in the latter 2008-2017 period. 


\begin{tabular}{rrrrrrrr}
\hline \hline to Real Gold & Start & Full Sample & $1973-2017$ & $1975-2017$ & $1991-2017$ & Start-2008m 9 & $2008 \mathrm{~m} 10-2017$ \\
\hline \hline MB & 1950 & $0.8887_{<}$ & 0.9705 & 0.9045 & $0.7706_{<}$ & $0.8020_{<}$ & $0.834_{<}$ \\
MB-SWP & 1950 & $0.7126_{<}$ & $0.906_{<}$ & $0.8844_{<}$ & $0.4962_{<}$ & $0.4959_{<}$ & $0.8200_{<}$ \\
MB+DDep & 1959 & $0.8374_{<}$ & 0.9239 & $0.8286_{<}$ & $0.6155_{<}$ & $0.7484_{<}$ & $0.6548_{<}$ \\
MB-SWP+DDep & 1959 & $0.4822_{<}$ & $0.6748_{<}$ & $0.6781_{<}$ & $0.3253_{<}$ & 0.7122 & $0.5551_{<}$ \\
M1 & 1959 & 0.7128 & 0.8077 & 0.8456 & 0.4755 & 0.7948 & 0.1080 \\
M1-SWP & 1959 & $0.4588_{<}$ & 0.6514 & 0.5491 & $\mathbf{0 . 0 8 8 9}<$ & 0.8300 & 0.1145 \\
M2 & 1950 & 0.3291 & 0.4372 & 0.5991 & 0.6677 & $0.2165<$ & 0.5908 \\
M2-SWP & 1950 & $\mathbf{0 . 0 6 1 9}$ & 0.1291 & 0.1819 & $\mathbf{0 . 0 5 7 8}<$ & $0.2481_{<}$ & $\mathbf{0 . 0 3 3 9}$ \\
CPI & 1957 & $\mathbf{0 . 0 2 3 4}<$ & $\mathbf{0 . 0 5 0 6}$ & $\mathbf{0 . 0 0 8 9}$ & $\mathbf{0 . 0 1 5 5}$ & $\mathbf{0 . 0 1 4 6}<$ & 0.6753 \\
EXP5Y & 2003 & $0.8997_{<}$ & $\mathrm{N} / \mathrm{A}$ & $\mathrm{N} / \mathrm{A}$ & $\mathrm{N} / \mathrm{A}$ & 0.3449 & $0.3397<$ \\
EXPMICH & 1978 & $0.2104_{<}$ & $\mathrm{N} / \mathrm{A}$ & $\mathrm{N} / \mathrm{A}$ & $0.7968_{<}$ & $\mathbf{0 . 0 4 3 4}$ & 0.3400 \\
M1Divis & 1967 & 0.4462 & 0.4292 & 0.5826 & 0.7558 & 0.3841 & 0.9539 \\
M1Divis-SWP & 1967 & 0.4001 & 0.4585 & 0.3652 & $\mathbf{0 . 0 4 8}<$ & 0.4441 & $0.3705<$ \\
M2Divis & 1967 & 0.2206 & 0.2414 & 0.3916 & 0.9125 & $0.1181_{<}$ & 0.8967 \\
M2Divis-SWP & 1967 & $\mathbf{0 . 0 9 0 2}$ & 0.1111 & 0.1993 & 0.2562 & $0.1372_{<}$ & 0.3816 \\
\hline \hline
\end{tabular}

Note: $\mathrm{p}$ values in bold $(<0.10)$ indicate the presence of causality.

Subscript $"<"$ indicates reverse causality

Table 2: Causality to real gold price

\begin{tabular}{|c|c|c|c|c|c|c|c|}
\hline to Oil/Gold ratio & Start & Full Sample & $1973-2017$ & $1975-2017$ & $1991-2017$ & Start-2008m9 & $2008 \mathrm{~m} 10-2017$ \\
\hline $\mathrm{MB}$ & 1950 & $0.149_{<}$ & 0.4696 & 0.3808 & 0.5503 & $0.5377_{<}$ & 0.7825 \\
\hline MB-SWP & 1950 & $0.02_{<}$ & 0.1707 & 0.0342 & 0.0923 & $0.6695<$ & 0.2309 \\
\hline $\mathrm{MB}+\mathrm{DDep}$ & 1959 & $0.0481_{<}$ & 0.1601 & $0.0879_{<}$ & 0.1321 & $0.4415<$ & 0.2015 \\
\hline MB-SWP+DDep & 1959 & $0.0366_{<}$ & $0.1383<$ & $0.023_{<}$ & 0.0524 & $0.5073_{<}$ & 0.0693 \\
\hline M1 & 1959 & $0.1507_{<}$ & $0.3089<$ & $0.1367_{<}$ & $0.0713_{<}$ & $0.6941_{<}$ & 0.2947 \\
\hline M1-SWP & 1959 & $0.0004_{<}$ & $0.0057_{<}$ & $0.0005<$ & $0.0016_{<}$ & $0.7207<$ & 0.0031 \\
\hline M2 & 1950 & $0.6722_{<}$ & $0.796_{<}$ & $0.813_{<}$ & $0.2315_{<}$ & 0.8291 & $0.4188<$ \\
\hline M2-SWP & 1950 & $0.4433_{<}$ & $0.5443_{<}$ & $0.3823_{<}$ & $0.3026_{<}$ & 0.8184 & 0.0427 \\
\hline CPIE & 1957 & 0.0321 & 0.0014 & $0.5804<$ & 0.8658 & 0.0063 & 0.0516 \\
\hline CPI & 1950 & $0.1048_{<}$ & $0.1072_{<}$ & $0.3225_{<}$ & $0.0903_{<}$ & $0.0152_{<}$ & $0.6126_{<}$ \\
\hline EXP5Y & 2003 & 0.0017 & $\mathrm{~N} / \mathrm{A}$ & $\mathrm{N} / \mathrm{A}$ & $\mathrm{N} / \mathrm{A}$ & 0.7903 & 0.0092 \\
\hline EXPMICH & 1978 & $0.2094_{<}$ & $\mathrm{N} / \mathrm{A}$ & $\mathrm{N} / \mathrm{A}$ & $0.0128_{<}$ & $0.1526_{<}$ & $0.1777_{<}$ \\
\hline M1Divis & 1967 & $0.5318<$ & $0.6001_{<}$ & $0.3863_{<}$ & 0.2475 & $0.6241_{<}$ & 0.7606 \\
\hline M1Divis-SWP & 1967 & $0.0087_{<}$ & $0.0175_{<}$ & $0.0019_{<}$ & $0.0014_{<}$ & $0.6538_{<}$ & 0.0018 \\
\hline M2Divis & 1967 & $0.5808<$ & $0.6847_{<}$ & $0.6058<$ & $0.121_{<}$ & $0.8882<$ & 0.3128 \\
\hline M2Divis-SWP & 1967 & $0.6857_{<}$ & $0.7416_{<}$ & $0.5621_{<}$ & $0.4088_{<}$ & $0.8861_{<}$ & 0.0704 \\
\hline
\end{tabular}

Note: $\mathrm{p}$ values in bold $(<0.10)$ indicate the presence of causality.

Subscript " $<$ " indicates reverse causality

Table 3: Causality to Oil/Gold price ratio 


\begin{tabular}{|c|c|c|c|c|c|c|}
\hline to Exch Rate & Start & Full Sample & $1975-2017$ & $1991-2017$ & Start-2008m9 & $2008 \mathrm{~m} 10-2017$ \\
\hline $\mathrm{MB}$ & 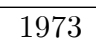 & $0.1862_{<}$ & $0.2221_{<}$ & $0.1557_{<}$ & 0.8803 & $0.0285_{<}$ \\
\hline MB-SWP & 1973 & $0.4269_{<}$ & $0.4725_{<}$ & $0.496_{<}$ & 0.6024 & 0.0752 \\
\hline $\mathrm{MB}+\mathrm{DDep}$ & 1973 & 0.3385 & 0.3642 & $0.3496<$ & 0.9056 & $0.1049_{<}$ \\
\hline MB-SWP+DDep & 1973 & 0.3987 & 0.4205 & 0.6351 & 0.7276 & 0.1432 \\
\hline M1 & 1973 & 0.2451 & 0.1882 & 0.2745 & 0.8167 & 0.7234 \\
\hline M1-SWP & 1973 & 0.0233 & $0.0408_{<}$ & $0.0786_{<}$ & 0.5833 & $0.2508_{<}$ \\
\hline M2 & 1973 & 0.2447 & 0.156 & 0.123 & 0.5582 & 0.9102 \\
\hline M2-SWP & 1973 & $0.163<$ & $0.1298<$ & 0.1178 & 0.4786 & 0.5678 \\
\hline CPI & 1973 & $0.0488_{<}$ & $0.0571_{<}$ & $0.0227_{<}$ & $0.0825_{<}$ & $0.0000_{<}$ \\
\hline EXP5Y & 2003 & $0.7937<$ & $\mathrm{N} / \mathrm{A}$ & $\mathrm{N} / \mathrm{A}$ & 0.5741 & $0.2233_{<}$ \\
\hline EXPMICH & 1978 & $0.0450_{<}$ & $\mathrm{N} / \mathrm{A}$ & $0.0010_{<}$ & 0.1015 & 0.4785 \\
\hline M1Divis & 1967 & 0.2039 & 0.1336 & 0.0314 & 0.9214 & 0.2844 \\
\hline M1Divis-SWP & 1967 & 0.049 & $0.0803_{<}$ & $0.1338<$ & 0.7689 & 0.7387 \\
\hline M2Divis & 1967 & 0.0962 & 0.059 & 0.0289 & 0.3907 & 0.5327 \\
\hline M2Divis-SWP & 1967 & 0.0522 & $0.0444_{<}$ & 0.0602 & 0.3122 & 0.8328 \\
\hline \multicolumn{7}{|l|}{ to Inflation } \\
\hline MB to CPI & 1947 & 0.0029 & 0.001 & $0.0013_{<}$ & 0.0237 & 0.0929 \\
\hline MB-SWP to CPI & 1947 & $0.0011_{<}$ & $0.0026_{<}$ & $0.0076_{<}$ & 0.0044 & $0.0245_{<}$ \\
\hline
\end{tabular}

Note: $\mathrm{p}$ values in bold $(<0.10)$ indicate the presence of causality.

Subscript $"<"$ indicates reverse causality

Table 4: Causality to the Exchange rate and to Inflation

M2Divis-SWP shows causality for the full sample; M1-SWP and M1 Divis-SWP show causality only for 1991-2017; short run inflation expectations (EXPMICH) cause gold prices for the Start-2008 period. Also of interest, the CPI Granger predicts gold prices in all subperiods except for 2008-2017. This suggests that the norm of inflation Granger predicting gold prices broke down post-2008 when the expected inflation did not materialize.

The nominal influence on both oil and gold prices, suggests an alternative way of normalizing the nominal oil price. Instead of dividing the dollar oil price by the US CPI, the dollar oil price is divided by dollar gold price. The causality testing of this alternatively normalized oil price is presented in Table 3.

Results are similar to the tests on oil prices alone with some results from the gold prices also appearing. For M1 minus Swaps (M1-SWP) and M1-Divisia minus Swaps, the results are similar, except for example no causality results in the 2008-2017 period for MB-SWP, in contrast to the oil price findings. However, there is Granger predictability by M1-SWP, M1Divis-SWP, M2-SWP, and M2Divis-SWP to the oil-gold price ratio in the 2008-2017 period; in contrast causality of real oil prices is found only for narrower than M2 aggregates in the 2008-2017 subperiod, while predictability of real gold prices is found only for a broader aggregate in that subperiod, this being M2-SWP.

Granger predictability is found for inflation expectation in a way almost identical to the 
oil price findings. For all of the Granger predictability findings in Table 3 for the 2008-2017 sample, in the last column, no reverse causality is found. ${ }^{4}$ Table 4 presents some further extensions.

Table 4 examines Granger predictability of the US dollar trade-weighted exchange rate index by the range of nominal factors reported in other tables, plus it reports tests of the monetary base in Granger predictability CPI inflation. The monetary base (MB), and the base minus Swaps (MB-SWP), significantly cause the exchange rate index only in the 20082017 subperiod. For three different subperiods, M1 minus Swaps, M2-Divisia and M2-Divisia minus Swaps all Granger predict the index; these subperiods are the "full sample", 19752017 and 1991-2017. M1-Divisia minus Swaps has similar results except for no predictability in 1991-2017.

Granger predictability by the CPI is robust for all the subperiods. Short run inflation expectation (EXPMICH) cause exchange rates for the full sample and for 1991-2017. The last two tests indicate Granger predictability of inflation by the MB and MB-SWP, for all periods, and with some reverse predictability found.

Granger predictability from MB to the CPI during the 2008-2017 subperiod are border line, while stronger for MB-SWP to the CPI. While inflation may not have been as high as was expected by markets, such if all the excess reserves instead had remained near zero during 2008-2017, inflation did jump from -1.96\% in July 2009 to $2.81 \%$ in December 2009, as banks initially recapitalized their solvency. This recapitalization could well have been helped by the Fed's mortgage-backed security (MBS) purchases, which went from zero in December 2008 to $\$ 1.1$ trillion in April 2010; even if the Fed bought only high-grade MBS, this could have helped banks to resume normal operations quickly. With excess reserves, minus the Swaps, mirroring the level of the MBS, this potential recapitalization may have contributed to the jump in the inflation rate that at the same time was correlated with the jump in excess reserves minus Swaps; this could explain finding Granger predictability from the MB-SWP to the CPI for the 2008-2017 subperiod.

\section{Discussion}

The results show significant evidence of money supply, the CPI, and inflation expectations Granger predicting real oil prices. Also money supply growth Granger predicts inflation, as has been found before (Haug and Dewald, 2012). And money growth and inflation predict international gold prices, the oil to gold price ratio, and the US dollar exchange rate index. This is a robust set of monetary facts that reinforce how nominal factors affect oil prices.

The additional facts make clear that oil prices are effected by monetary aggregates in a fashion related to other asset prices. Granger predictability is found for gold prices, by the

\footnotetext{
${ }^{4}$ Note that the starting date for the gold price is 1950, as compared to 1946 for oil; probably the difference is negligible in that the US was on the Bretton Woods gold standard from 1946-1950.
} 
M2 minus Swaps (M2-SWP) aggregate, with less robust results for narrower aggregates. In contrast, it is the narrower aggregates, of the monetary base minus Swaps (MB-SWP), M1 minus swaps (M1-SWP) and M1-Divisia minus Swaps, that Granger predict oil prices.

Gold is a bit different from oil in usage in that oil needs to be used much so for day to day production of output. Real gold prices appear to build in shorter term expectations of inflation while the real oil prices build in both long and short run inflation expectations. For the 2008-2017 period, only the longer term inflation expectations Granger predict oil prices.

The Granger predictability results of the oil/gold price are similar to the oil price results. A notable difference is that in the 2008-2017 period, the oil/gold price ratio is Granger predicted also by M2 minus Swaps, while the oil prices are not so effected. This implies that post Great Recession, the broader aggregate provides what might be valuable information on expectations of inflation.

If so, this may have resulted because the interest on excess reserves kept the reserves from being lent out and expanding the M1 aggregate in the typical money multiplier fashion; this could then have resulted in giving M2 additional weight even for shorter term inflation expectations. While this oil/gold price ratio provides additional information for considering oil shocks, inference on short term versus long term inflation expectations is preliminary here; other measures of inflation expectations could be experimented with, a topic left for future research.

The results overall provide support for the notion that nominal factors played a role in the oil price shock during and after the Great Recession. And a role for inflation expectations is part of the results. Results show that long term inflation expectations Granger predicted real oil prices with no reverse predictability in the 2008-2017 period.

The 5-Year Breakeven Inflation Rate fell approximately by half from its 2014 peak at $2.03 \%$ on June 23,2014 to its trough of $1.05 \%$ on January 13, 2015. When the excess reserves finally peaked in August, 2014, at $\$ 2.7$ trillion, expectations of future inflation had begun to fall and then collapsed, nearly in perfect time with oil prices. WTI oil prices peaked on June 20,2014 at $\$ 107.95$ and fell until January 28,2015 , to $\$ 44.08$, closely in line with the change in the breakeven measure of inflation expectations.

\section{Conclusion}

The evidence presented in this paper indicate how nominal factors Granger predict real oil prices including the Great Recession period and afterwards, once Swaps are subtracted from the aggregates. The results suggest that the post - 2008 expansion of the monetary base increased inflation expectations. Inflation expectations are found to predict oil prices, and the collapse of both inflation expectations and oil prices in 2014 was coinciding. 
The speculation from these results is that the 2009-2014 oil shock resulted because extra expected inflation was built into oil prices until 2014, but the extra inflation was not realized because of indirect "sterilization" of part of the monetary base through the holding of excess reserves. An important next step in this research is to use Kilian's (2009) impulse response analysis to test whether monetary factors help explain oil shocks when added to the key components of supply and demand that Kilian provides.

\section{References}

Alquist, Ron and Kilian, Lutz and Vigfusson, Robert J., 2013. "Forecasting the Price of Oil," Handbook of Economic Forecasting, Elsevier.

Barsky, Robert B. and Kilian, Lutz, 2004. "Oil and the Macroeconomy Since the 1970s," Journal of Economic Perspectives, 18 (4, Fall):115-134.

Baumeister, Christiane and Kilian, Lutz . 2016, "Forty Years of Oil Price Fluctuations: Why the Price of Oil May Still Surprise Us", Journal of Economic Perspectives; 30 (1, Winter): 139-160.

Blinder, Alan S. and Lutz Kilian, 2009, "Comments and Discussion on Causes and Consequences of the Oil Shock of 2007-08.", Brookings Papers on Economic Activity, Vol. 2009, Spring; pp. 262-283.

Bordo, Michael D. and Humpage, Owen F., and Schwartz, Anna J. 2014. "The Evolution of the Federal Reserve Swap Lines since 1962", NBER Working Paper No. 20755, December.

Friedman, Milton, 1994, Money Mischief: Episodes in Monetary History, Harcourt Brace \& Company, New York.

Giles, David, 2011. "Testing for Granger Causality", Econometrics Beat: Dave Giles' Blog; April 29, 2011.

Gillman, Max \& Nakov, Anton, 2009. "Monetary effects on nominal oil prices," The North American Journal of Economics and Finance, 20 (3, December): 239-254.

Gram, Phil and Saving, Thomas R. 2017. "A Booming Economy Will Challenge the Fed", Wall Street Journal, Dec. 13.

Granger, C. W. J. 1969. "Investigating Causal Relations by Econometric Models and Cross-spectral Methods." Econometrica, 37 (3, Aug.): 424-438.

Hamilton, J. D. 1983. "Oil and the macroeconomy since World War II". Journal of Political Economy, 91(2), 228-248.

Hamilton, J. D., 2009, "Causes and Consequences of the Oil Shock of 2007-08", Brookings Papers on Economic Activity, Vol. 2009, Spring; pp. 215-261.

Haug, A. A., and W. G. Dewald. 2012. "Money, Output and Inflation in the Longer Term: Major Industrial Countries, 1880 - 2001." Economic Inquiry 50 (July), 773-787.

Kilian, Lutz, 2009. "Not All Oil Price Shocks Are Alike: Disentangling Demand and Supply Shocks in the Crude Oil Market," American Economic Review, vol. 99(3), pages 
1053-1069, June.

Lucas, Robert Jr., 1988. "On the mechanics of economic development," Journal of Monetary Economics, 22 (1, July): 3-42.

Lucas, Robert E. and Nicolini, Juan Pablo, 2015. "On the stability of money demand," Journal of Monetary Economics, 73(C): 48-65.

Mabro, Robert, 1984. "On Oil Price Concepts", Oxford Institute for Energy Studies, WPM3.

Mankiw, Gregory, 2014. Principles of Economics, 7th Edition, South Western College Publishing, Nashville.

Toda, Hiro Y. and Yamamoto, Taku. 1995. "Statistical inference in vector autoregressions with possibly integrated processes". Journal of Econometrics, 66 (1-2): 225-250. 